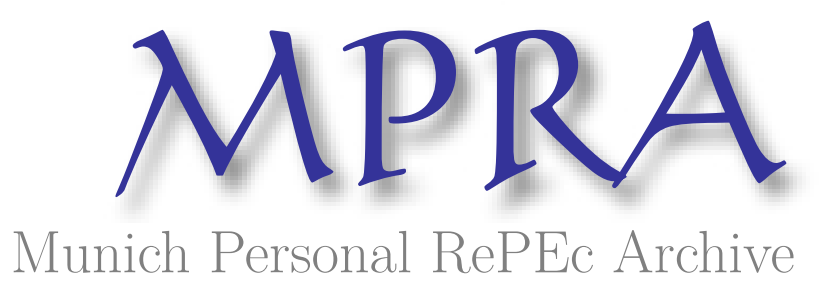

\title{
Current Mobile Payment Procedures on the German Market from the View of Customer Requirements
}

Pousttchi, Key and Zenker, M.

University of Augsburg

2003

Online at https://mpra.ub.uni-muenchen.de/2911/

MPRA Paper No. 2911, posted 14 May 2007 UTC 


\section{Current Mobile Payment Procedures on the German Market from the View of Customer Requirements}

\author{
Key Pousttchi \\ University of Augsburg, \\ Wirtschaftsinformatik II (Business Informatics) \\ e-mail: key.pousttchi@wiwi.uni-augsburg.de
}

\author{
Mario Zenker \\ VIRBUS AG \\ Chief Technology and Development Officer \\ e-mail:mzenker@virbus.de
}

\begin{abstract}
The key to mobile payment acceptance is in the hands of customers. In this paper we use the results of the mobile payment survey MPI in order to identify and roughly weigh the most relevant acceptance criteria. The outcome of the paper is an evaluation scheme containing the covered payment scenarios, important main criteria (security, costs and convenience) and additional functionality requirements for each MP procedure. The scheme is based on empirical results and can assess a given MP procedure with regard to customer acceptance as well as to compare different procedures. The operational MP procedures Paybox, I-mode and Vodafone m-pay are examined and compared according to the scheme. Finally, a prospect is given to possible further development of mobile payment procedures in the direction of an integrative universal mobile payment system (UMPS).
\end{abstract}

\section{Introduction}

According to the sweeping enthusiasm that characterized much of the news reporting in the years 1999 and 2000 mobile phones should by now have been firmly established as payment terminals in the most diverse fields. Reality today is a different matter though. Mobile payment as an established payment system still seems to be a distant prospect.

We define mobile payment (MP) as that type of payment transaction processing in the course of which within an electronic procedure - (at least) the payer employs mobile communication techniques in conjunction with mobile devices for initiation, authorization or realization of payment. [9] For purposes of this paper, we refer to the term payment systems whenever we discuss a general payment method such as cash, electronic payment or MP. We refer to the term payment procedures whenever we talk about concrete solutions such as m-pay, Paypal or (the former) Paybox. [6]

The key to acceptance of MP procedures is in the hands of customers [10]. In this paper we rely on the considerations on acceptance criteria in [6], [10] and on the empirical results of the mobile payment survey MP1 in order to evaluate the operational MP procedures on the German market from the view of customer requirements.

In section 2 , we identify relevant acceptance criteria. In section 3, we use these to develop an evaluation scheme which is used in section 4 to evaluate and compare the three operational solutions on the German market. In section 5 we draw conclusions, explain major shortcomings of the solutions and show important influences and developments in the MP market evolution.

The empirical statements on customer acceptance made in section 2 are derived from the results of the mobile payment survey MP1 which was conducted by the University of Augsburg in October and November 2002. For more details on the methodology of MP1 see [5].

\section{Customer requirements to MP procedures}

Mobile payment is crucial for, but not limited to Mobile Commerce. Instead, an MP transaction can take place in four different general settings, distinguished with regard to the point of sale or service [6]:

- the mobile commerce scenario $(M C)$,

- the electronic commerce scenario (EC),

- the stationary merchant scenario, which can occur as stationary merchant scenario (person), e.g. to pay in a department store, for a taxi or a pizza service, and stationary merchant scenario (automat),

- the customer-to-customer scenario (C2C).

Besides the claim of applicability in all scenarios, the requirements can be divided into three categories [6]:

- security which includes not only integrity, authorization, authentication, confidentiality and nonrepudiation of transactions, but also the issue of subjective security from the customer's perspective,

- costs which include direct transaction costs and fixed costs of usage plus the cost of the technical infrastructure for the customer (e.g., a new mobile phone),

- convenience which includes any issues related to ease and comfort of use.

In order to keep the scheme to develop in section 3 as simple as possible, we refer for each of the categories to the most relevant two respectively three criteria. The shown principle can - mutatis mutandis - be extended to all criteria enquired in MP1. 
Pousttchi, K.; Zenker, M.: Current Mobile Payment Procedures on the German Market from the View of Customer Requirements. In: Proceedings of the DEXA 2003 Workshop on Mobile Commerce Technologies and Applications (MCTA 2003). Prague, 2003. (preprint)

The two most relevant criteria of the category security are shown in table 1. Confidentiality of data is the central security feature of every MP procedure. Behind confirmation we see the functionality requirements cancellation and anonymity fall in this category. The latter is an important subject among the considerations of experts, but did not prove its significance in MP1 (66\% approval).

Table 1. Approval for criteria of the category security

\begin{tabular}{|l|c|}
\hline \multicolumn{1}{|c|}{ criterion } & approval \\
\hline confidentiality of data & $96 \%$ \\
confirmation of the payment via SMS or e-mail & $89 \%$ \\
\hline
\end{tabular}

The two most relevant criteria of the category costs are shown in table 2. None or low costs refers to direct costs of the procedure (basic and transaction fees).

Table 2. Approval for criteria of the category costs

\begin{tabular}{|l|c|}
\hline \multicolumn{1}{|c|}{ criterion } & approval \\
\hline none or low costs & $92 \%$ \\
purchase of a new mobile device not necessary & $83 \%$ \\
\hline
\end{tabular}

As the most relevant criteria of the category convenience each represent own important concepts, we present these three instead of two criteria for this category (table 3).

Table 3. Approval for criteria of the category convenience

\begin{tabular}{|l|c|}
\hline \multicolumn{1}{|c|}{ criterion } & approval \\
\hline easy handling & $93 \%$ \\
fast processing of the payment transaction & $91 \%$ \\
high number of accepting merchants & $85 \%$ \\
\hline
\end{tabular}

The two most relevant criteria which are functionality requirements and were not assigned to one of the above categories are shown in table 4.

Table 4. Approval for criteria which are special functionality requirements

\begin{tabular}{|l|c|}
\hline \multicolumn{1}{|c|}{ criterion } & approval \\
\hline execution of a bank transfer possible & $47 \%$ \\
payment of amounts < 20ct possible & $33 \%$ \\
\hline
\end{tabular}

For more detailed comments on acceptance criteria see [1], [5], [7], [9], [10].

\section{Development of an evaluation scheme}

Based on the results of section 2 we will now develop a scheme for the evaluation of MP procedures. Following these results, an MP procedure will be most likely to become widely accepted by customers if it

- covers all payment scenarios,

- ensures confidential treatment of data,

- issues payment confirmations via SMS or e-mail,

- incurs none or little costs for customers,

- does not oblige customers to buy a new mobile device,

- is easy to handle and responds quickly,

- is accepted by a high number of merchants,

- is suitable for the execution of bank transfers,

- is suitable for picopayments (amounts below 20 cents). In order to make these factors comparable, we use a simple evaluation matrix and determine a score.
As a general rule, each category gets a maximum number of points reflecting its relevance to acceptance. This maximum number is equally portioned between the criteria of the category. A procedure is assigned all points if the criterion has been fully met, half of the points if the criterion has been partially met and no points if the criterion has not been met at all.

Because of the high importance in the competition against other payment systems as well as against other MP procedures, we assigned 6 points to the coverage of the scenarios with regard to $\mathrm{MC}$, stationary merchant and EC. The $\mathrm{C} 2 \mathrm{C}$ scenario has been neglected due to its low importance to the customer decision. [5], [9]

Table 5. Evaluation scheme for MP procedures from the view of customer requirements

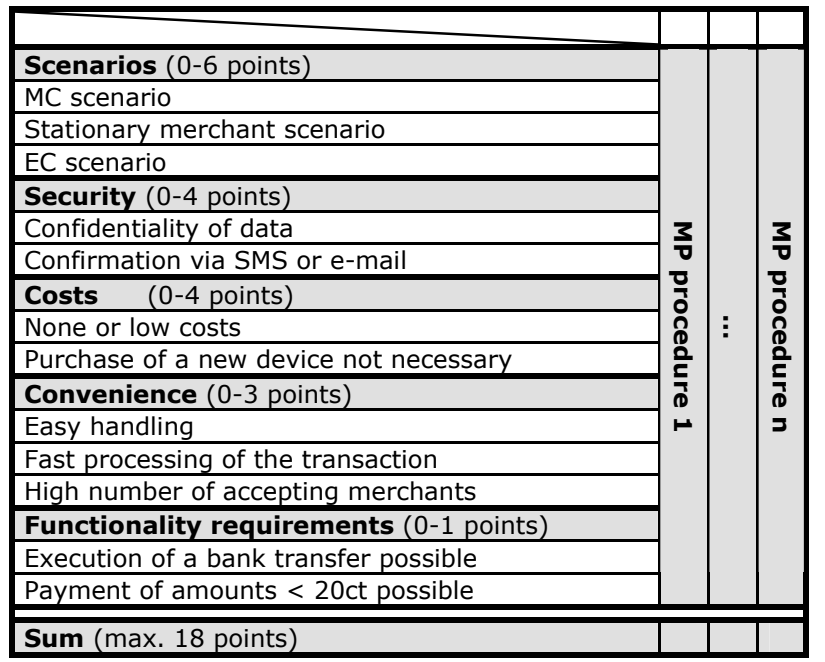

Each of the categories security and costs has been assigned 4 points. Though being also very relevant, convenience pales in direct comparison to the latter two (as proved through the examination of relative relevance in [9]) and thus has been assigned only 3 points. The two functionality requirements execution of a bank transfer possible and payment of amounts $<20$ ct possible contribute little to the acceptance of the procedure. They are assigned 1 point in order to round off the evaluation. The aggregation of the named criteria with their assigned point values results in the evaluation matrix depicted in table 5. MP procedures can be assessed and ranked according to their achieved overall score.

\section{Rating of current German MP procedures}

\subsection{Market overview}

The German MP market saw a lot of trials in the past years, operated by mobile network operators (MNO), banks/financial service providers (FSP) or specialized MP intermediaries [6]. One of the authors was involved in the development, implementation and operation of some of these. Of the MP procedures available in 2002 and 2003 we decided that only three can be considered 
Pousttchi, K.; Zenker, M.: Current Mobile Payment Procedures on the German Market from the View of Customer Requirements. In: Proceedings of the DEXA 2003 Workshop on Mobile Commerce Technologies and Applications (MCTA 2003). Prague, 2003. (preprint)

truly operational in the sense of being operated for profitoriented purposes and having a relevant number of customers: Paybox which was the established market leader until its cessation of service in early 2003 , the integrated payment procedure of i-mode and Vodafone m-pay. In sections 4.2 to 4.4 , these will be assessed in turn. Section 4.5 shows a comparison using the proposed scheme.

\subsection{Paybox}

The most well-known MP procedure in Germany is Paybox. The operator of the procedure was a technologydriven payment startup which falls in the category of specialized intermediaries. Having started in May 2000 the service was the first mover in its field. Paybox acted not only as a payment intermediary, but also actively acquired merchants and offered them the technical solution to integrate Paybox in their systems. Within 3 years Paybox enrolled more than 500,000 customers and 6,500 merchants. Payments were authorized using IVR (Interactive Voice Response). [8] Paybox is a procedure of the MP standard type conventional settlement. [6]

Scenarios. The particular way of authenticating payments imposed restrictions on the use of Paybox within the MC scenario. For example, Paybox could not be used for WAP services since the customer during a WAP session could not be called to conduct the authorization. Paybox was especially targeted to the stationary merchant and EC scenario. One of the most actively marketed incidence of use was paying a cab. Customers could pay their bill by mobile phone after the cab driver had entered the customer's MS ISDN into his device and Paybox had called the customer back for authorization. Besides this kind of payment other kinds of automat-based payments had been piloted.

Security. The confidential treatment of data was vouched for by Paybox. This guarantee was obviously sufficient for Paybox customers. Paybox managed to boost and solidify their reputation not only by marketing efforts, but also by a number of test runs and awards won. For the confirmation of payments a number of options were supported depending on the kind of transaction and on the payment scenario, including SMS and e-mail.

Costs. The annual basic fee was $10 €$, transaction fees did not exist. As it can be assumed that an important part of customers enrolled with a $50-100 \%$ discount on the basic fee, the high number of customers does not allow any inference on the acceptance of high basic fees. Paybox could be used with any mobile phone. Thus preliminary costs were low and facilitated customers' participation.

Convenience. The procedure was easy to use and understand as the customer only had to know his MS ISDN and could rely on the IVR system to guide him through the transaction or authorization process. Customer experience in the handling of voice-based transactions afforded Paybox the reputation of an easy-to-use and subjectively safe system. Fast processing of transactions was possible, although it largely depended on the customer's speed in handling the system. Compared with other MP procedures Paybox boasted a very high diffusion.

Functionality Requirements. Bank transfers through Paybox were possible. Picopayments were technically possible yet not efficient since costs for the used debit procedure and the system's call-back function tended to outweigh transaction amount.

Assessment. Paybox reaches a good score within the scheme (15.50 out of 18). Among the system's shortcomings its sub-optimal capacity within the MC scenario, the recurrent costs for customers and its deficiencies in operating picopayments have to be noted critically. For a detailed overview of scores see section 4.5.

\subsection{I-mode}

The inherent payment procedure of i-mode is an MP procedure that can only be used within the i-mode MC platform. Customers cannot make payments within any other payment scenario than MC. Notwithstanding this limitation i-mode serves as an instructive example as its information and entertainment portal offers the full range of MC and is designed especially with a focus on paying for content. It has been operated exclusively by the MNO E-Plus since early 2002. Basic technology as well as the underlying MP procedure are under license from the Japanese company NTT DoCoMo. With more than 123,000 subscribers (as of 02-2003) and 140 content providers (as of 11-2002) i-mode up to now has a significantly smaller customer and merchant base than Paybox. To realize a payment, the amount is displayed and the user just asked to press a button in order to authorize and confirm the payment. [2] I-mode inherent payment is a procedure of the MP standard type phone bill. [6]

Scenarios. The MP procedure is limited to the MC scenario, e.g. to pay for news or the purchase of tickets.

Costs. The payment does not generate additional transaction fees for customers. I-mode itself can only be used if an E-Plus customer both subscribes to i-mode (monthly basic fee, minimum $5 €$ ) and purchases a special i-mode mobile phone. Subscribers from competing MNO are excluded from the service.

Security. Responsibility for both the confidential treatment of data during payment procedures and the safe handling of customers' data lies with E-Plus. The latter is also safeguarded by NTT DoCoMo's i-mode technology. Customers have confidence in the well-known MNO EPlus. Thus, its reputation enhances a feeling of security in customers and the criterion of subjective security is satisfied. Confirmation of payment is handled via a special confirmation page displayed on the mobile device informing the customer about the outcome of a transaction.

Convenience. The i-mode MP procedure is easy to use and understand. Payment-related data as a rule do not have to be entered. Thus, the extent of customer experi- 
Pousttchi, K.; Zenker, M.: Current Mobile Payment Procedures on the German Market from the View of Customer Requirements. In: Proceedings of the DEXA 2003 Workshop on Mobile Commerce Technologies and Applications (MCTA 2003). Prague, 2003. (preprint)

ence necessary to handle the system tends to be very low. This may have contributed to the system's overwhelming success in Japan. The average duration of payment procedures is below that of Paybox, since no authorization and authentication call is required. Instead, GSM-inherent authentication is used and authorization of a payment simply takes the pressing of a button. Again, the speed of a transaction is largely determined by the customer's speed in handling the system. Thus customers tend to experience i-mode as a fast-working system.

Functionality Requirements. The requirement of a capacity for the execution of a bank transfer is only partially met. Picopayments can be easily performed since these can be aggregated; the MP procedure has been specifically designed for this kind of payment.

Assessment. The i-mode MP procedure treats the typical $\mathrm{MC}$ scenario based on revenue sharing. The ample range of services within i-mode's information and entertainment portal and the underlying MP procedure present customers with a viable and easy to use mobile service solution. Among i-mode's deficiencies are the restriction to the MC scenario, the obligation to become an E-Plus subscriber in order to use i-mode, the necessity to buy a special mobile device and the lack of a bank transfer functionality. These weaknesses are the reasons for the imode score which is relatively low (11.25 out of 18 points). For a detailed overview of scores see section 4.5.

\subsection{Vodafone m-pay}

The latest MP procedure of the three is Vodafone mpay. Devised for the MC scenario but also usable in EC, it can up to now handle payments up to a maximum of 10 $€$ (although this is a deliberate restriction in order to gain experience with the procedure). Operation of m-pay started in September 2002. In contrast to Paybox and imode, m-pay customers do not have to specially register to be able to use the procedure, but the use is limited to Vodafone customers (credit or prepaid). Currently there is no indication of the total number of m-pay users. With regard to participating merchants and content providers Vodafone specified a total of 2 merchants for the EC scenario and 20 content providers. [11] Vodafone m-pay is a procedure of the MP standard type phone bill. [6]

Scenarios. Different operating sequences cover payment within the two respective scenarios. For the MC scenario payment is WAP-based. Recognizing the customer MS ISDN assures fail-proof and convenient authentication. As for i-mode, authorization is done by pressing a button. For the EC scenario, the customer enters his mobile phone number in a web form and receives an SMS from the payment server. This SMS contains the content provider's name along with a specification of the content requested and a six-digit TAN. The customer can now complete the EC transaction by entering the TAN and then receives a confirmation of the payment on a web page. For the stationary merchant scenario payment pro- cedures could technically be the same as for EC but no implementation exists yet.

Costs. The use of m-pay does not entail extra costs for customers, i.e. there are neither basic nor transactions fees. This includes even the SMS being sent by the payment server within the EC scenario. Purchase of a special device other than a WAP-enabled phone is not required.

Security. Security requirements like the confidential treatment of data are met. No payment-related data are transmitted from customers to content providers or merchants during the transaction, since these data have been stored by the payment server and used only internally. As with i-mode, customers tend to assign the status of a trusted party to the well-known MNO Vodafone. Thus the criterion of subjective security is satisfied. Customers are informed about the outcome of a transaction, receiving a payment confirmation via the web within the EC scenario or via the mobile phone within the MC scenario.

Convenience. M-pay is basically easy to use and understand. Duration of payment procedures is similar to that of i-mode within the MC scenario and thus comparatively low. In the EC scenario the procedures take slightly more time since the forwarding and entering of a TAN is required. Again, the most important factor here is the customer's speed in handling the procedure, thus customers tend to experience m-pay as a fast-working system. As far as merchant participation is concerned, m-pay is - up to now - at a great disadvantage.

Functionality Requirements. As with i-mode the regular MNO billing system is used to process payments. The requirement of a direct bank transfer is met only partially. Picopayments pose no problem since the procedure has been specially designed to enable those.

Assessment. M-pay covers the MC, EC and (principally) the stationary merchant scenario, meets the most important requirements for the category costs and partially satisfies requirements for the category functionality requirements. Thus Vodafone m-pay achieves a very good score (16.75 out of 18 points). The fact that no further registration is required is bound to facilitate spontaneous use. The major deficiency is the small number of participating merchants and content providers. Thus this important criterion has been evaluated at 0 points. Since market entry is relatively recent it is to be expected that Vodafone can overcome this drawback and offer an MP procedure that comes very close to customer expectations. For a detailed overview of scores see section 4.5.

\subsection{Aggregation of the results}

The aggregation of the detailed assessment results of sections 4.2 to 4.4 is depicted in table 6 .

None of the procedures reaches the top score since various shortcomings detracted from the procedures' effectiveness. It is apparent, however, that each carries a burden that might deter customers from usage: Paybox' 
Pousttchi, K.; Zenker, M.: Current Mobile Payment Procedures on the German Market from the View of Customer Requirements. In: Proceedings of the DEXA 2003 Workshop on Mobile Commerce Technologies and Applications (MCTA 2003). Prague, 2003. (preprint)

lack of payment in the MC scenario, i-mode's inability to cover scenarios others than MC and the insufficient number of merchants and content providers for m-pay.

Table 6. Evaluation scheme for operational MP procedures on the German market

\begin{tabular}{|l|c|c|c|}
\hline & $\begin{array}{c}\text { Pay- } \\
\text { box }\end{array}$ & $\begin{array}{c}\text { i- } \\
\text { mode }\end{array}$ & $\begin{array}{c}\text { m- } \\
\text { pay }\end{array}$ \\
\hline Scenarios (0-6) & & & \\
\hline MC scenario & 1 & 2 & 2 \\
\hline Stationary merchant scenario & 2 & 0 & 2 \\
\hline EC scenario & 2 & 0 & 2 \\
\hline Security (0-4) & & & \\
\hline Confidentiality of data & 2 & 2 & 2 \\
\hline Confirmation via SMS or e-mail & 2 & 2 & 2 \\
\hline Costs (0-4) & & & \\
\hline None or low costs & 1 & 2 & 2 \\
\hline No Purchase of a new device & 2 & 0 & 2 \\
\hline Convenience (0-3) & & & \\
\hline Easy handling & 1 & 1 & 1 \\
\hline Fast processing & 1 & 1 & 1 \\
\hline Accepting merchants & 1 & 0.5 & 0 \\
\hline Functionality requirements (0-1) & & & \\
\hline Bank transfer possible & 0.5 & 0.25 & 0.25 \\
\hline Payment < 20ct possible & 0 & 0.5 & 0.5 \\
\hline Sum (max. 18 points) & 15.50 & 11.25 & 16.75 \\
\hline
\end{tabular}

As already pointed out in section 1 , the presented scheme covers only part of the criteria for a sustained acceptance of an MP procedure. But closer examination of the market reality and of the customer behavior lead to the conclusion that the simple evaluation matrix already gives a good estimation of customer acceptance. Presently, Vodafone m-pay seems to have the best opportunity to mend its deficiencies. However, as we see with the example of Paybox, a good customer acceptance does by no means supply sufficient proof of sustained viability on the market.

\section{Conclusions and perspectives}

Apart from direct customer acceptance, two further issues are highly relevant to the market evolution. The first issue concerns the different (potential) mobile payment service providers and their specifics (see also section 4.1). MNO and banks/FSP operate on existing reliable customer relationships while mostly using their available infrastructure and thus optimizing its workload. Specialized intermediaries operate an MP procedure as their core business, acting under the pressure to generate revenues recovering the costs for their whole infrastructure. Even if such a company (like Paybox did) succeeds in contracting large numbers of customers and participating merchants, gets favorable media coverage and establishes a brand with enormous marketing efforts, its revenue model still remains difficult. MNO desperately need MP for setting up their MC scenario and possess knowledge and infrastructure to settle the appropriate amounts, typically micro- and picopayments. Banks/FSP on the other hand possess the knowledge and infrastructure to settle especially macropayments, typically in the stationary mer- chant scenario. But as we already argued in section 2, an MP market breakthrough will not happen with procedures only covering single scenarios (or payment heights).

The second issue deals with standardization and market fragmentation. While one of Paybox' keys to success was the independence from a specific MNO and bank/FSP, current procedures operated by MNO are only available for their respective subscribers. We would see the same effect with banks/FSP; in a cooperation MNObank (like e.g. Postbank-O2 in the Netherlands) the m:n problem would be even worse. Few of the resulting procedures, if any at all, would be interesting to merchants.

This would dramatically change if a merchant could assume that with the acceptance of just one more payment system (or even just procedure) he could address any mobile phone user. This could be realized through standardized MP procedures with centralized billing, a solution alike the credit card market. Another approach could be the development of an integrative universal mobile payment system (UMPS) based on an abstraction layer above the procedure level. This UMPS would have to be user-centered and allowed to use any given payment procedure on any given mobile device and network with any given merchant and financial service provider interface. A respective solution would allow maintaining the variety of existing MP procedures and the variety of mobile devices. At the same time, customers as well as merchants could be relieved of the need to occupy themselves with the payment problem for mobile solutions.

\section{References}

[1] Cheong, Y.C.; Tan, C.-L.: Payments in Mobile Commerce. Singapore 2001

[2] E-Plus: Informations on i-mode. (URL: http://www. eplus.de, browsed 04-17-2003)

[3] Graumann, S.; Köhne, B.: Monitoring Information Age Society. 5. Report. NFO Infratest GmbH. München 2002. (URL: http://193.202.26.196/bmwi/main2002_11.asp, browsed 03-15-2003)

[4] Henkel, J.: Mobile Payment. In: Silberer, G.; Wohlfahrt, J.; Wilhelm, T. (Hrsg.): Mobile Commerce. Wiesbaden 2002.

[5] Khodawandi, D.; Pousttchi, K.; Wiedemann, D. G.: Akzeptanz mobiler Bezahlverfahren in Deutschland. In: Pousttchi, K.; Turowski, K. (Eds.): Mobile Commerce - Anwendungen und Perspektiven. Proceedings zum 3. Workshop Mobile Commerce. Bonn 2003.

[6] Kreyer, N.; Pousttchi, K.; Turowski, K.: Standardized Payment Procedures as Key Enabling Factor for Mobile Commerce. In: Bauknecht, K.; Quirchmayr, G.; Tjoa, A M. (Eds.): E-Commerce and Web Technologies. EC-Web 2002. Aix-en-Provence 2002.

[7] Kruppa, S.: Mobile Payment. Beyond the M-Commerce Hype. Stuttgart 2002.

[8] Paybox: Informations on Paybox. (URL: http:// www.paybox.de/3416.html, browsed 01-17-2003)

[9] Pousttchi, K.: Conditions for Acceptance and Usage of Mobile Payment Procedures. In: Proceedings of the M-Business 2003 Conference. Wien 2003. (Preprint)

[10] Pousttchi, K; Selk, B; Turowski, K.: Acceptance Criteria for Mobile Payment Procedures. In: Hampe, F.; Schwabe, G. (Eds.): Mobile and Collaborative Business 2002. Nürnberg 2002.

[11] Vodafone: Informations on m-pay. (URL: http://www. vodafone.de/m-pay/27437.html, browsed 04-17-2003) 